\title{
An Automated Maintenance Management Program
}

Part I: Quantitative Assessment of the Exterior Condition of Metal Buildings and Roofing Systems via Computer Image Processing

Jonathan W. Martin

Dale P. Bentz

Lawrence Kaetzel

Mary E. McKnight

U.S. DEPARTMENT OF COMMERCE

National Bureau of Standards

National Engineering Laboratory

Center for Building Technology

Gaithersburg, MD 20899

March 1988

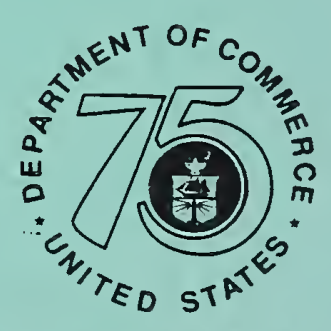

Stimulating America's Progress
1913-1988

Prepared for:

Tri-Services

Building Materials Investigation Program 
NBSIR $88-3719$
AN AUTOMATED MAINTENANCE
MANAGEMENT PROGRAM
PART I: QUANTITATIVE ASSESSMENT OF
THE EXTERIOR CONDITION OF METAL
BUILDINGS AND ROOFING SYSTEMS
VIA COMPUTER IMAGE PROCESSING

Jonathan W. Martin

Dale P. Bentz

Lawrence Kaetzel

Mary E. McKnight

\author{
U.S. DEPARTMENT OF COMMERCE \\ National Bureau of Standards \\ National Engineering laboratory \\ Center for Building Technology \\ Gaithersburg, MD 20899
}

March 1988

Prepared for:

Tri-Services

Building Materials Investigation Program

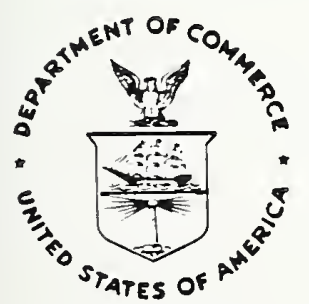

U.S. DEPARTMENT OF COMMERCE, C. William Verity, Secretary NATIONAL BUREAU OF STANDARDS, Ernest Ambler, Director 

TABLE OF CONTENTS

ABSTRACT. . . . . . . . . . . . . . . . . iii

LIST OF FIGURES . . . . . . . . . . . . . . . iv

1. INTRODUCTION. . . . . . . . . . . . . . 1

2. COMPUTER IMAGE PROCESSING . . . . . . . . . . . 3

2.1 IMAGE ACQUISITION . . . . . . . . . . . . . 3

2.2 IMAGE DIGITALIZATION. . . . . . . . . . 4

2.3 COMPUTER PROCESSING OF DIGITAL IMAGES . . . . 5

2.3.1 Computer Image Processing Hardware . . . 5

2.3.2 Computer Image Processing Software . . 6

2.4 IMAGE DISPLAY • • • . . . . . . . . . . 10

3. EXTERIOR CONDITION ASSESSMENT VIA COMPUTER IMAGE. • . 10 PROCESSING

3.1 EXTERIOR CONDITION ASSESSMENT EXAMPLES. . • • 12

3.2 SAMPLING CONSIDERATIONS •. . . . . . . . . 14

4. INTEGRATION OF IMAGE PROCESSING INTO THE AUTOMATED. - 15 MAINTENANCE PROGRAM

5. SUMMARY . . . . . . . . . . . . . . 17

6. ACKNOWLEDGEMENTS. . . . . . . . . . . . 17

7. REFERENCES. . . . . . . . . . . . . . . 18

APPENDIX A - TERMINOLOGY • . . . . . . . . . . . . 19

APPENDIX B - IMAGE PROCESSING BIBLIOGRAPHY . . • . . 21

APPENDIX C -- SAMPLE IMAGE PROCESSING SYSTEM. • . . . 22 CONFIGURATIONS 



\section{ABSTRACT}

Automation of a maintenance management program could result in considerable benefits in terms of time, money, and aesthetics to any facility's maintenance program. An integrated system combining computerized condition assessment, database management, and expert systems could serve to automate the maintenance management process. One part of such a system, the use of computer image processing to quantitatively assess the exterior condition of buildings, is presented. Computer image processing hardware and software are reviewed and the special concerns present in applying image processing to condition assessment are addressed. Examples of the capability of image processing to quantify the degradation of coated surfaces and roofing systems are presented. Finally, the integration of image processing into an overall automated maintenance management program is discussed.

Keywords: Computer image processing; condition assessment; database management; degradation; exterior envelope; sampling procedures. 



\section{LIST OF FIGURES}

Fig. 1. Hypothetical degradation versus time curves for two buildings

Fig. 2. The effect of greylevel resolution on an image:

8 greylevels versus 256 greylevels.

Fig. 3. Noisy and time-averaged thermograms.

Fig. 4. Corrosion spots (original and binary).

Fig. 5. Side of building (original and differentiated).

Fig. 6. Steel structures Painting Council No. 4 rusting standard (original and processed).

Fig. 7. Federation of Societies for Coatings Technology's chalking standard.

Fig. 8. Peeling paint from side of building (original and processed).

Fig. 9. Thermograms of wet roofs (original and processed).

Fig. 10. Aggregate removal from a room (original and processed).

Fig. 11. Side of building from three different distances. 



\section{INTRODUCTION}

Funds for the maintenance of facilities of military installations are usually limited. To maximize the return on these funds, proper maintenance decisions are required. Proper decisions require knowing the existing condition, rate of deterioration, and environment of all facilities and cost of potential repairs. With this knowledge, prioritization of maintenance actions and proper materials selections can be made. Currently, because of limited personnel, condition assessment procedures are very qualitative and may not even be carried out for all facilities. Hence, procedures are needed to obtain condition assessment quickly using the available personnel and to archive this information for future referral. Automating the condition assessment process using computer image processing could be a way to obtain and preserve this information and thereby improve the cost effectiveness of maintenance actions.

With the rapid evolution of computer technology, creation of an automated maintenance management program has become economically viable. The core of the system would be a maintenance database containing cost, material, environmental, and degradation information. This database could be organized to rank structures on the basis of their assessed condition, estimated repair costs, or in other desired ways. The quantitative assessment of the condition of a structure can be provided by a computer image processing system. Using photographs, videotape, or other images of a structure, computer image processing can quantify the degradation shown in the images. This information will then be available for automatic input into a database management system, which can provide a historical record of the condition of each structure in the maintenance supervisor's inventory. The final element in the automated maintenance system would be an expert system to extract pertinent information from the databases and make recommendations on materials and procedures for the repair of structures and to minimize maintenance costs or to meet other management objectives. These recommendations would be based on knowledge provided by experts in the maintenance area. The integration of these three computer tools: image processing, database management, and expert systems constitutes an automated maintenance management program.

This paper addresses in detail one part of the automated system, exterior condition assessment via computer image processing. Currently, when carried out, the exterior envelope of structures is assessed by inspectors using subjective descriptors such as good, poor, or failed (1). The weaknesses of this procedure are that assessments may be influenced by the biases of the inspector. The assessments provided by computer 

image processing, on the other hand, are fast and quantitative, and should be unbiased. Since the images can be conveniently stored in digital format, using an optical disk for example, they can be sequentially retrieved so as to follow the progressive degradation of a structure. This will enable the generation of a degradation versus time curve which can be utilized in optimally scheduling maintenance of a structure. Figure 1 shows two hypothetical curves for the first five years of a building's life. For Building $A$, the rate of degradation has levelled off, after a high rate of initial degradation, and therefore repair can be postponed if necessary. Conversely, Building B could require immediate repair as it has reached a critical point beyond which the degradation is increasing exponentially with time.

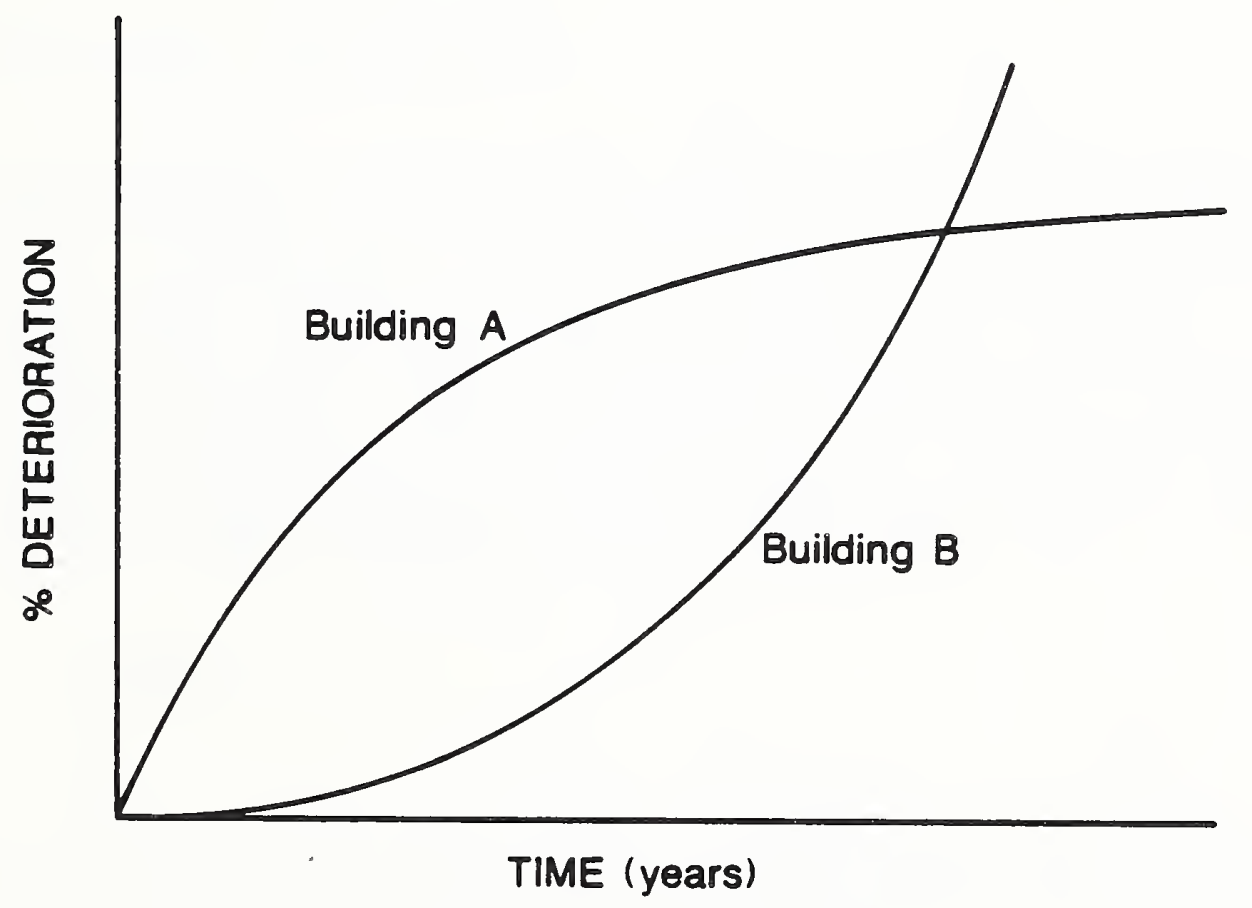

Fig. 1. Hypothetical degradation versus time curves for two buildings.

Successful application of computer image processing to exterior condition assessment requires consideration of several factors. The computer image processing system must be selected to serve the immediate needs of the user while allowing for expansion. Standardized sampling procedures must be developed to accurately assess and quantify the degradation of a structure while minimizing the effort expended in collecting this information. Also, different types of degradation must be weighted differently in determining the exterior condition of a 

structure. For example, the degradation of structural components should be given more weight than non-structural components. To effectively execute maintenance strategies, the information provided by image processing must be transferred to the database system so that repair need can be prioritized and materials selected.

This paper provides a plan for making maintenance decisions. Image processing hardware and software are reviewed and the special considerations for applying computer image processing to exterior condition assessment are addressed. Examples of the ability of computer image processing to quantify the degradation of various structures are provided. The interfacing of the image processing system with the rest of the automated maintenance system is discussed. Appendices include image processing terminology and typical imaging system configurations.

\section{COMPUTER IMAGE PROCESSING}

Computer image processing involves the enhancement, analysis, and classification of images to obtain useful information. In general, computer image processing can be divided into four steps (2): 1) obtaining an image, 2) analog to digital conversion of this image, 3) computer processing of the image in digital form, and 4) conversion of the processed image back to analog form for viewing purposes. Each of these steps places certain requirements on the hardware and/or software comprising the image processing system.

\subsection{IMAGE ACQUISITION}

While all of the above four steps are necessary, obtaining the image is crucial in that only those features which are present in the image can be characterized. For example, one should not expect to quantify small cracks in a painted substrate by photographing the whole side of a building. Here, a smaller area will have to be photographed such that the cracks are visible in the photograph. In addition to visual images, images can be obtained using an infrared thermography camera (to identify emission differences) or other techniques from which a photographic print can be obtained. If possible, photographs should be obtained at an angle normal to the exterior surface so that the degradation can be accurately quantified. If this is not done, it will be necessary to mathematically reorient the image to produce a normal representation. 

The second step in processing an image involves converting the image into a digital format. Generally, this is accomplished by viewing the image source with an imaging camera whose output is sent in a standard format (such as RS-170) to an image digitizing board contained in the main computer. The digitized image can then be permanently stored for later reference.

During the analog to digital conversion, the image is resolved into a series of picture elements, pixels, whose assigned integer value depends on the intensity of the incoming analog signal. The key consideration in selecting an image digitizer is the resolution, both spatial and greylevel. spatial resolution refers to the number of pixels in an image and is a measure of the systems' ability to accurately isolate objects (defects) from the background. At present digitizers with $512 * 512$ (columns * rows) are readily available, with $1024 * 1024$ and $4096 * 4096$ systems being available for specialized applications. Typical greylevel resolutions are 8, 16, 64, and 256. The human eye can resolve about 40 greylevels so that a digitizer with a minimum greylevel resolution of 64 ( 6 bit resolution) is needed to produce images which appear continuous to a human observer. The effect of greylevel resolution is illustrated in Figure 2 where the same image is shown with 8 greylevels and 256 greylevels. As the number of greylevels increase, it is easier to isolate features in an image.
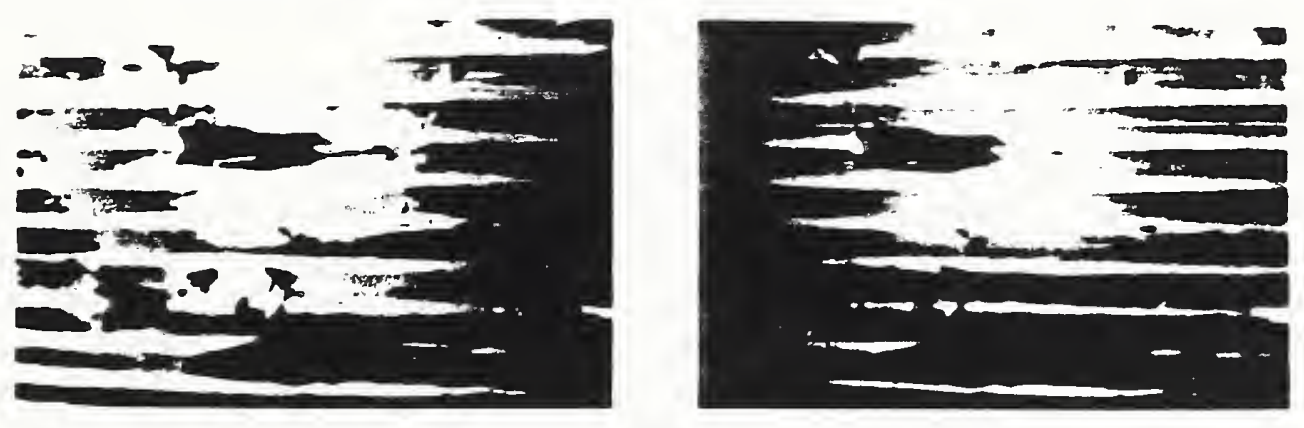

Fig. 2. The effect of greylevel resolution on an image: 8 greylevels versus 256 greyscale levels. 

other considerations for an image digitizer include the noise level and linearity of the digitalization and compatibility between camera and digitizer. Although software can overcome some deficiencies in the areas of noise and linearity, it is best to choose a digitizer with high linearity and a low noise level. Above all, the digitizer board must be capable of accepting the analog signal from the camera to which it is attached.

Since the storage of digitized images requires large amounts of memory (262 Kbytes for a 512*512 image with 256 greylevels), major consideration must be given to the storage capability of the image processing system. When a large number of images must be stored, the system should include a removable hard disk or an optical disk. One $51 / 4$ inch optical disk can typically hold up to a Gigabyte or approximately four thousand images. Current technology in this field (WORM -Write once Read Many) does not allow unwanted files to be deleted and replaced; this may be a benefit to an automated maintenance plan, since the major emphasis will be on archiving images for future reference.

\subsection{COMPUTER PROCESSING OF DIGITAL IMAGES}

While the first two steps in processing an image mainly depend on obtaining the proper hardware and image capture, the actual computer processing of the digitized image relies heavily on both hardware and software. A successful system requires that hardware and software be developed concurrently and that each takes full advantage of the other's capabilities.

\subsubsection{Computer Image Processing Fardwa:e?}

The major hardware components for processing digitized images are image processing boards, the main computer, and peripheral hardware devices to assist the user of the system. Image processing boards perform a variety of functions. Framebuffer boards provide the space to hold one image in active memory where each pixel can be accessed and/or modified. Most image processing systems contain at least one frame buffer board, although sometimes this capability is provided within the image digitizing board. In systems containing multiple frame buffer boards, specialized image processing boards (containing arithmetic logic units) provide the capability to quickly combine two or more images (such as subtracting a background image). other specialized boards exist to generate a greylevel histogram (a histogram of the number of pixels occupying each of the possible greylevels) or perform other image processing functions. The advantage of hardware-based image processing algorithms, as opposed to software-based algorithms, is that they reduce 

processing time (some algorithms can actually be performed in real time) and they relieve the host computer of specialized tasks. The disadvantage is the general lack of flexibility provided by the hardware.

The computer is the unifying element in an image processing system. The imaging boards, peripheral devices, and software cannot be specified until the computer has been selected. In the past, only mainframe computers were able to handle the calculation-intensive tasks required of an image processing system. Although larger computers are generally faster and provide more memory for the execution of complicated image processing algorithms, complete systems are now available which are centered around the personal computer found on a typical researcher's desk. Personal computers have many advantages over dedicated mini-, or even main frame, computer image processing systems including portability, low cost, and 100 percent dedication to image processing. Several image processing system configurations along with estimated costs are provided in the Appendix C.

Other hardware items involved in the computer processing of digitized images are the peripheral devices ranging from line printers, for printing analysis results, to a joystick or mouse to select areas of an image for further processing. These items vary from system to system and must be specified so that they are compatible with the selected computer.

\subsubsection{Computer Image Processing Software}

Computer processing of digital images consists of three stages (2): preprocessing, enhancement, and classification.

The purpose of preprocessing is to obtain a digital image which suitably represents the original image source. Noise removal is one goal of preprocessing. Random noise can often be eliminated by time-averaging a series of incoming images. If additive random noise is present, averaging $\mathrm{N}$ incoming images will improve the signal-to-noise ratio (SNR) by the square root of N. This process is illustrated in Figure 3 which shows a thermographic image and the improvement obtained by averaging eight consecutive incoming frames. If the incoming image is spatially non-uniform (e.g. the image is darker on the edges than in the center), image subtraction can be used to eliminate much of the non-uniformity present in the image.

The second step in digital image processing is image enhancement. Here, the goal is to produce an image which is easily interpreted. Image enhancement algorithms can be either pixel transformations (point operations), neighborhood 

transformations (local operations), or geometric transformations. In point algorithms, the resultant greylevel value for each pixel in the digitized image is dependent only on the greylevel value of that pixel in the input image. The most often used point operation is thresholding. In thresholding, all pixels within a user-specified range ( $0-30$ for example) are assigned a new greylevel value of 0 while all other pixels outside this range are assigned another greylevel value (255 for example). The result is a high contrast, so-called binary image, which will optimally contain dark objects on a light background. These binary images are much more readily interpretable (i.e. the size and shape of each object can be easily determined) than the original images as is shown in Figure 4.
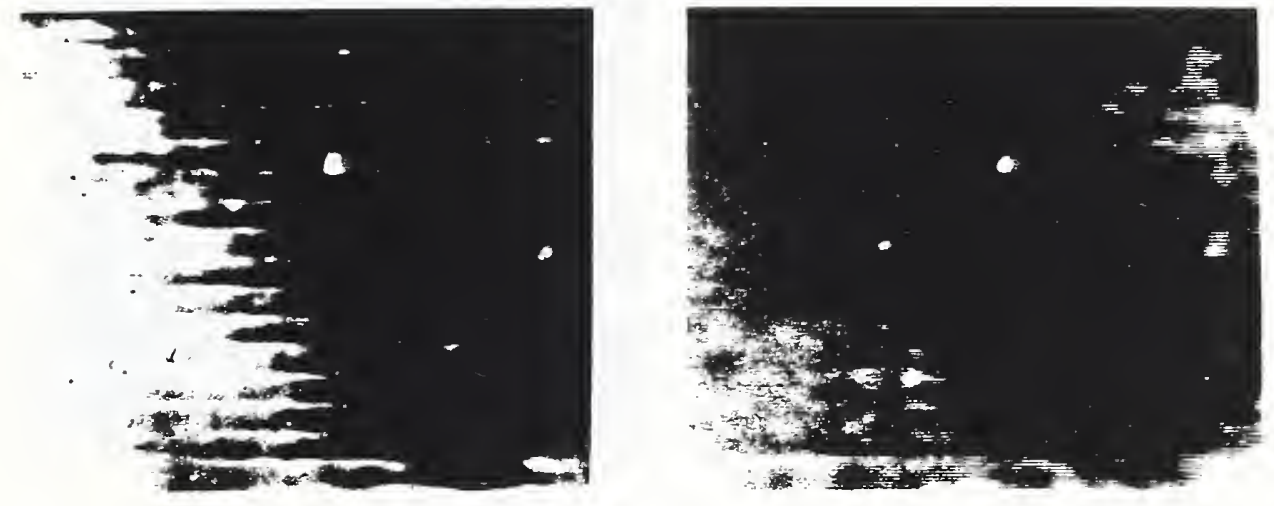

Fig. 3. Noisy and time-average thermograms.

Another example of a point operation is a color lookup table. In imaging systems capable of color (RGB - red,green, blue) display, color can be used to highlight objects of interest. For example, the two greyscale levels in the binary image in Figure 4 can be depicted in color as opposed to white and black. In designing a color lookup table, one assigns a color triple $(R, G, B)$ to each of a number of greylevel ranges (e.g. 0 to 255). Then, each pixel in turn is assigned a display color based on that pixel's original greylevel value.

In neighborhood operations, the resultant greylevel value of each pixel depends on the original greylevel values of that pixel and $a$ set of surrounding pixels (such as a $3 * 3$ box of pixels centered at the pixel of interest). Filtering is an example of a 

neighborhood operation. Here, the greylevel values of each pixel in the original neighborhood are weighted by some factor, the resultant values are summed, and the resulting sum is rescaled and assigned to be the output greylevel value for the pixel at the center of the neighborhood box. The time necessary to perform a filtering operation can be reduced if an arithmetic logic unit board contained in the image processing system can be used for both combining images and filtering. Two enhancement filters are the low-pass filter, used to reduce noise and smooth the image, and the high-pass filter, used to sharpen edges.
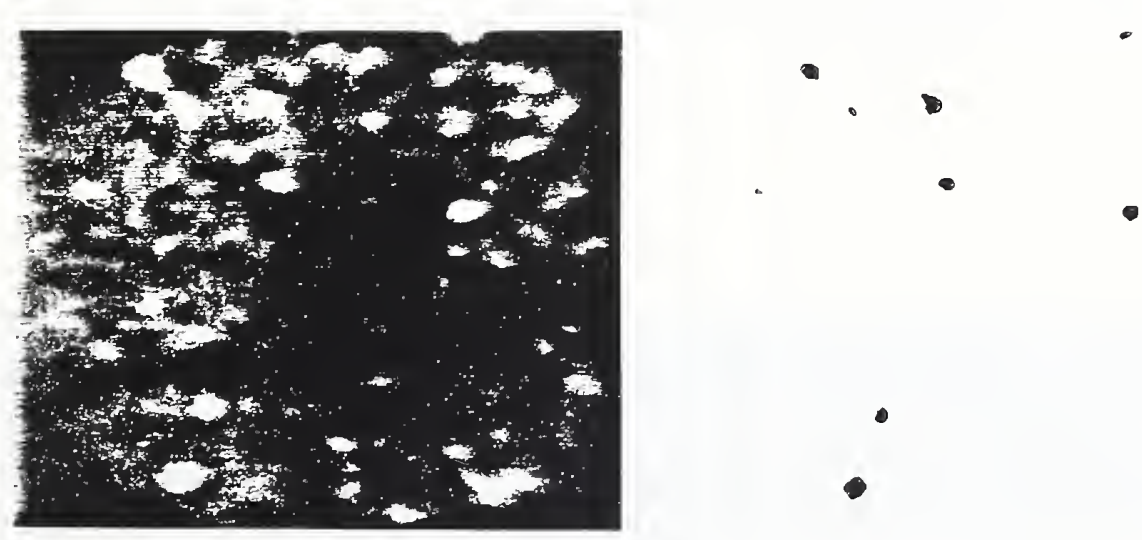

Fig. 4. Corrosion spots (original and binary).

A neighborhood operation useful for detecting edges of objects or separating objects on the basis of texture is differentiation or gradient filtering. Here, the maximum difference between each pixel and its surrounding eight pixel neighborhood is assigned as the output pixel value. This technique is illustrated in Figure 5 which shows the original and differentiated images of the side of a building containing corrosion defects.

In geometric transformations, the orientation, scaling, and perspective of the original image are modified. The image may be rotated to reorient an area of interest for further processing. A warping operation may be useful if the original image is a distorted representation of the image source. Here, the user selects certain points in the image and informs the imaging 

system of where these points should actually appear in the image. The imaging system then applies a geometric transformation to the image to align these selected points with their desired locations.

The final step in computer processing of digital images is the classification or analysis of the enhanced image to obtain the final quantitative results. Depending on the application, the desired result may be the percentage of the image occupied by a particular feature (defects), the size, shape, and location of individual features, or another quantitative measure of degradation. If the enhanced image consists of black features on a white background (a binary image), these features can be easily characterized with respect to size, shape, and location or any other statistic of interest to the user (Figure 4 and Table 1). once such characterization is completed, the results should be placed in a format which allows for easy manipulation and integration into other parts of the automated maintenance program.

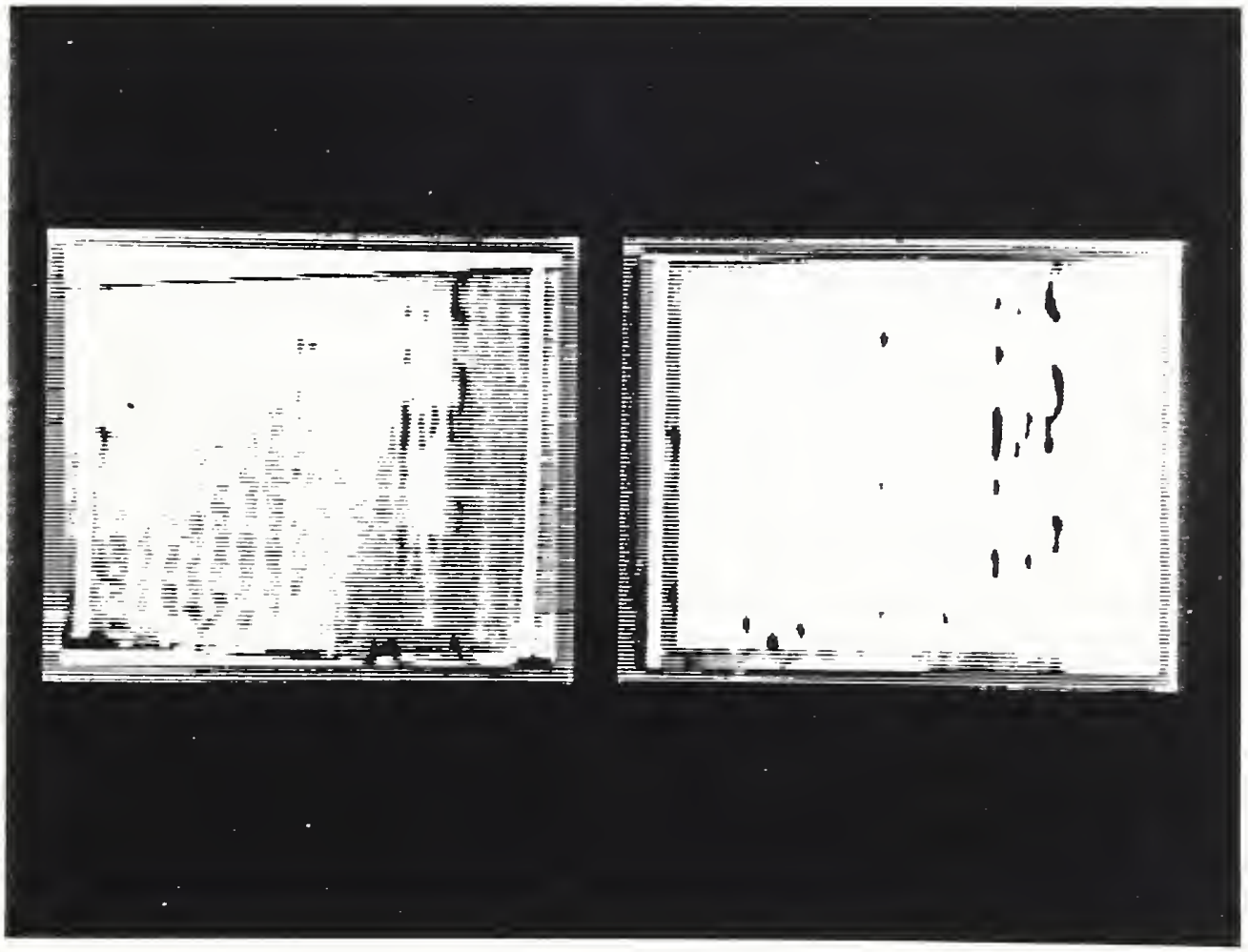

Fig. 5. Side of a building (original and binary). 

The final step in computer image processing is to convert the digital image back to analog form for output. output is generally classified into two categories: volatile or refresh (such as a TV screen) and permanent or hardcopy (such as a videoprinter). The resolution and linearity of the digital-toanalog converter and display device should be as good as those of the digitizer so that realistic images may be presented to the user of the system. In addition, the physical size of the display should be such that the smallest features of interest in an image can be easily recognized. If the image processing system is capable of color output, a color monitor or color videoprinter would be a useful addition to the system.

While the majority of image processing systems operate on black-and-white images, new systems are emerging which can extract color information from the image source. Color is represented by a color triple (red, green, blue) similar to the color assignment made in creating a color lookup table. The difference is that instead of each pixel being assigned a greylevel value between 0 and 255 during digitalization, each pixel is assigned three values between 0 and 255 (one each for red, green, and blue). These values are obtained by viewing the image source with a color camera which senses polychromatic radiation or a monochromatic camera which contains interchangeable red, green, and blue filters.

The advantage of color image processing is in the segmentation process, that is, separating defects from non-defect regions. In a black and white image, this is usually accomplished by a threshold operation, that is, the defects are uniquely contained and can be isolated in a certain greylevel range. Using color image processing, this separation can be made in color space where there is often more contrsst between defects and non-defect regions. For instance, red rust stains on an orange building are more readily separable in color space where one can take advantage of the yellow component of the orange color.

3. EXTERIOR CONDITION ASSESSMENT VIA COMPUTER IMAGE PROCESSING

To properly consider what features of an image processing system are most important in building condition assessment, one must first decide what a typical assessment procedure will be. one possible plan would be to take pictures of the site or structure to be assessed and return these pictures along with identification information to a central location which contains the image processing system. Here, a typical procedure would be 

to take the picture of the structure from the field, digitize and enhance the image in the laboratory, and then analyze the resultant image to determine the size, shape, and location of individual defects. This degradation information could then be stored and included in a database for future reference.

The above procedure would place certain requirements on the image processing equipment. The photographs obtained in the field must depict accurately the degradation of the structure so a high quality camera would be desirable. The resolution of the image digitizer board and size of the area photographed should be such that the smallest defects occupy several pixels in the digitized image.

The imaging program should ideally execute both in an interactive mode (where the operator has complete control over the imaging process) and also in a batch mode (where a series of commands are executed with no human intervention). Such a system would minimize manpower requirements in the image processing area while still providing flexibility in the imaging process. Since
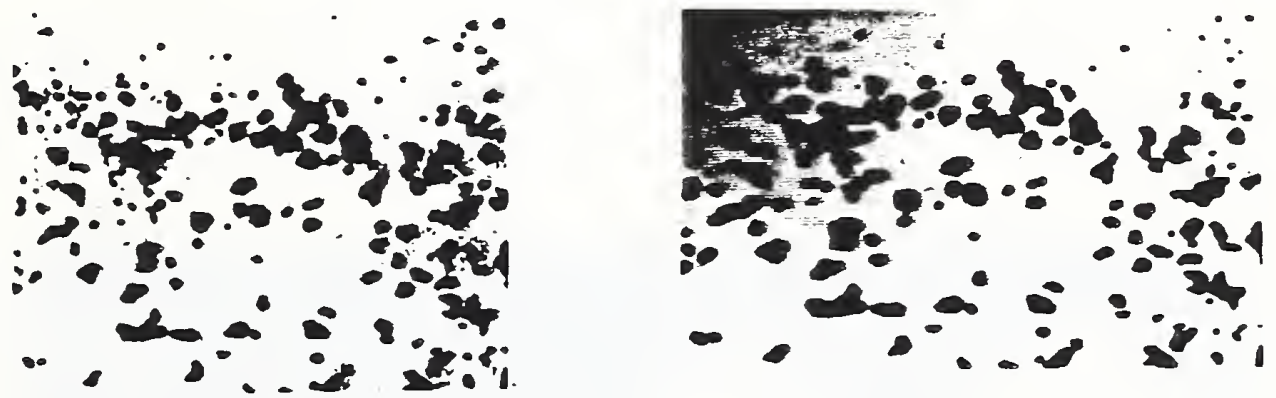

Fig. 6. Steel Structures Painting Council No. 4 rusting standard (original and processed).

photographs often contain structural and non-structural areas (e.g. the sky or trees), the image processing software should be such that the user can execute algorithms on only parts of images. As stated earlier, a joystick or mouse provides a convenient means for rapidly selecting "areas of interest" within an image. 

Obviously, for an automated maintenance program, computer storage of images will be a primary concern. Since it is desirable to store all of the digitized images for the development of structural histories, the imaging system should include a high capacity storage system such as a removable hard disk or an optical disk. Furthermore, the images must be uniquely and concisely labelled so that relevant images can be easily identified for future retrieval.

\subsection{EXTERIOR CONDITION ASSESSMENT EXAMPLES}

Computer image processing has been successfully applied to evaluating the degradation of painted surfaces (3) and roofing systems. For painted surfaces, Bentz and Martin (1987) demonstrated that computer image processing was applicable to the wide variety of coating defects by quantitatively evaluating the photographic visual standards for the different defect types $(4,5)$ (such as blistering, chalking, cracking, mildew, peeling, and rusting). The quantification of the ASTM D610, No. 4 photographic standard for rusting is illustrated in Figure 6 which shows the original and processed images. The percent area rusted determined by the image processing system was 13 percent.

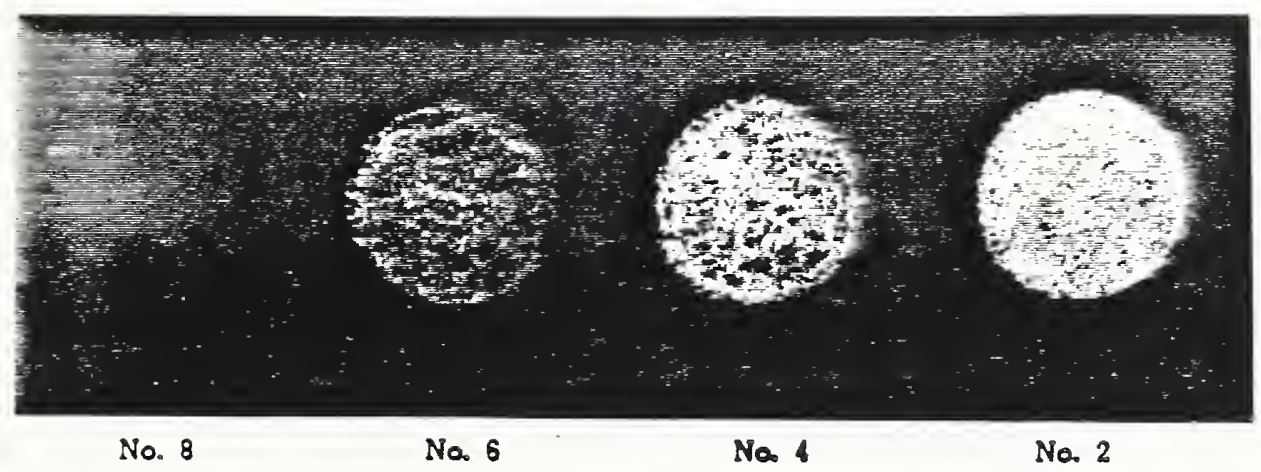

Fig. 7. Federation of Societies for Coatings Technology's chalking standard. 

Quantification of chalking degradation is different from the standard measure of degradation in that the percent area degraded is not a relevant parameter. Here, the discoloration of the cloth rubbed over the painted surface was quantified by determining the average greylevel of the discolored area. Figure 7 shows the photographic standard for chalking. The percent whiteness calculated for the No. $8,6,4$, and 2 standards in Figure 7 are 10, 35, 67, and 98 percent, respectively. This demonstrates the ability of computer image processing to quantify degradation in an application where degradation area is not a critical measure.
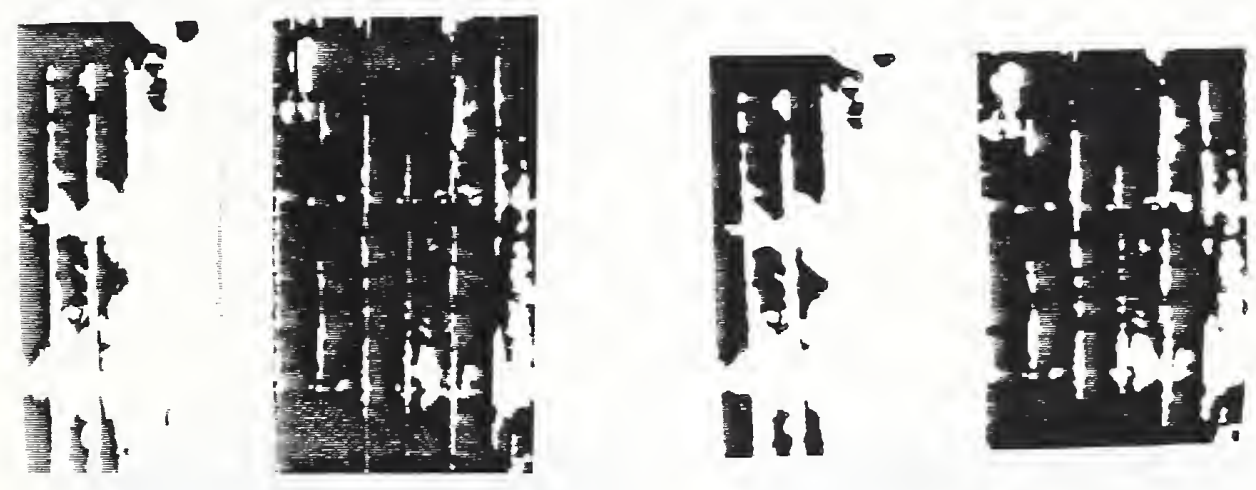

Fig. 8. Peeling paint from side of building (original and processed).

Computer image processing has also been used to quantify the degradation of coated structures and roofing systems. Figure 8 shows the original and processed images of the side of a metal building from which the applied coating has peeled. Via computer image processing, the peeled area was determined to occupy 48 percent of the area shown. In figure 9, a thermographic image of a building roof was photographed from a helicopter, the building had two appurtenances each of which was processed separately to isolate the wet regions (16 percent of the smaller and 35 percent of the larger roof are wet). Aggregate removal from a roofing system was also quantified using computer image processing as illustrated in Figure 10 ( 13 percent of the surface area shown was free of aggregate). In general, computer image processing has the capability of quantifying any building material defects which can be observed in the source image. 
In addition to image processing concerns, exterior condition assessment will require the development of sampling plans so that only a portion of a building has to be photographed to quantify its degradation state. One aspect of the sampling procedure is the size of the sampling area. Obviously, fewer photographs will be required if large areas are photographed. At the same time, a photograph is worthless if it does not depict the degradation state of a structure (i.e. if defects present are not visible in the photograph). Thus, the optimum sampling area is the largest in which individual defects can be readily discerned. If the defects are large, e.g. due to peeling, large sampling areas can be used; whereas, if the defects are small, e.g. pinpoint corrosion or small blisters, then small sampling areas must be photographed. This approach has been supported by photographing a building from three different distances and analyzing the same
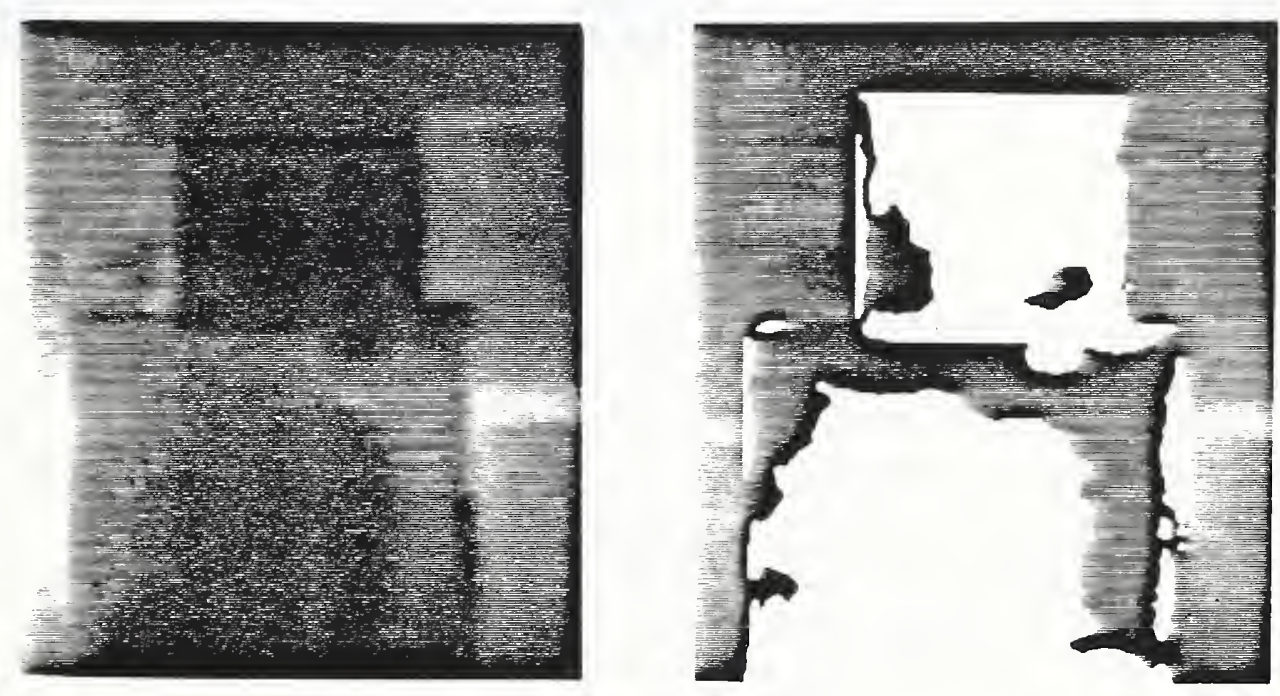

Fig. 9. Thermogram of wet roofs (original and processed).

area in each photograph for percent degradation. Figure 11 illustrates this procedure for one area, showing the area analyzed in each of the three images in binary (black-or-white) form. The degradation percentages determined in each case (15, 14, and 16 percent) are similar enough that any of the 

photographs could be used for accurately evaluating the degradation of this structure. In each photograph, the cracks present in the coating cladded to the building are readily distinguishable.

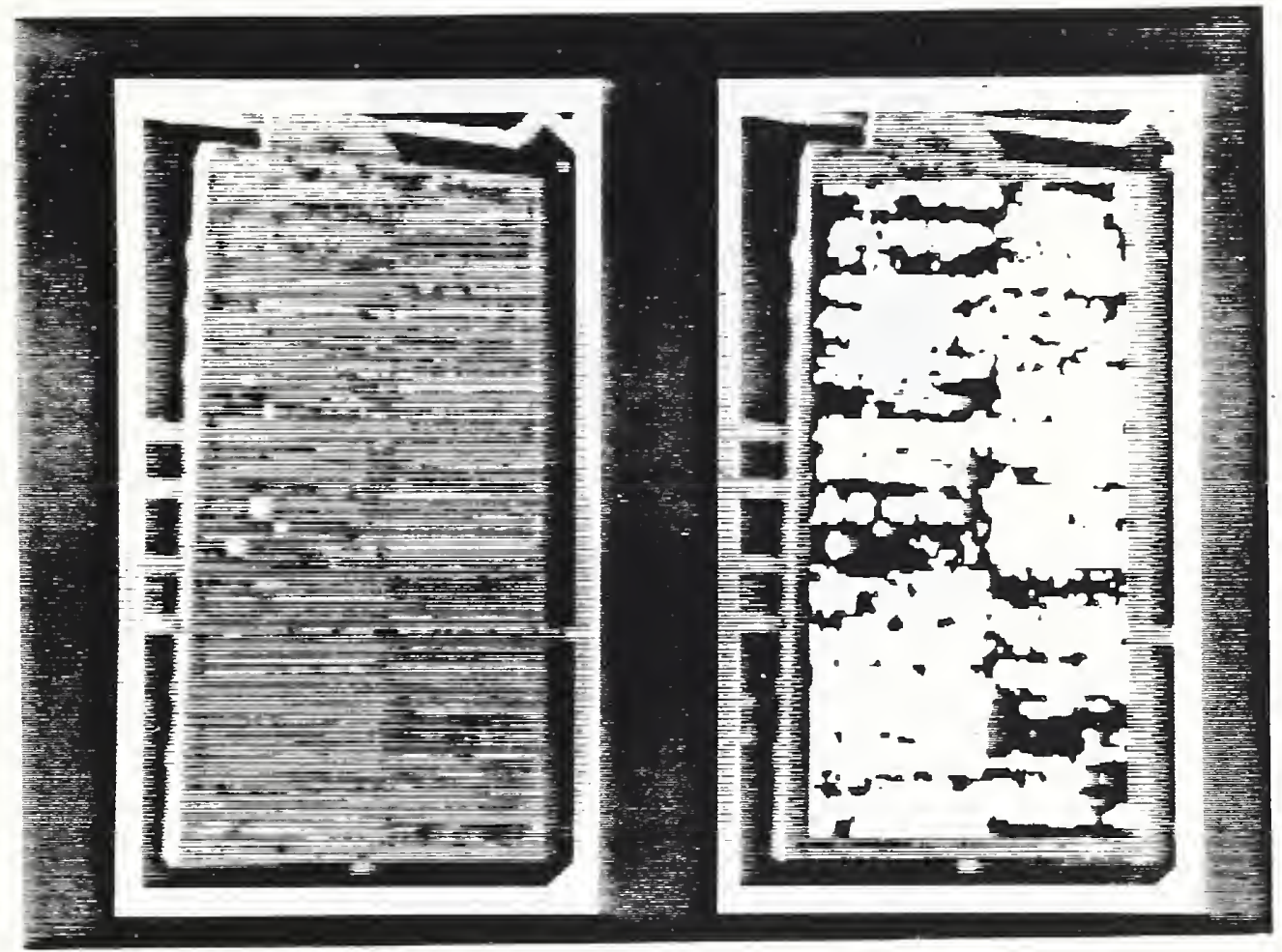

Fig. 10. Aggregate removal from a room (original and processed).

The other aspect of the sampling problem is how many photographs of various areas of a structure are necessary to quantify the degradation state of that structure. This will depend on whether the defects are clustered in various areas or randomly located over the structure. This is the type of information which should become available as the automated maintenance program is implemented and degraded spots of various structures are identified. These trouble spots can then be photographed along with a random sampling of the rest of the structure to accurately estimate the degradation.

\section{INTEGRATION OF IMAGE PROCESSING INTO THE AUTOMATED MAINTENANCE PROGRAM}

As stated in the introduction, image processing capabilities are only part of an automated maintenance management program. It is therefore important that the image processing system interface with database management and expert system modules contained within the automated program. The quantitative degradation information provided by image processing should be included in 


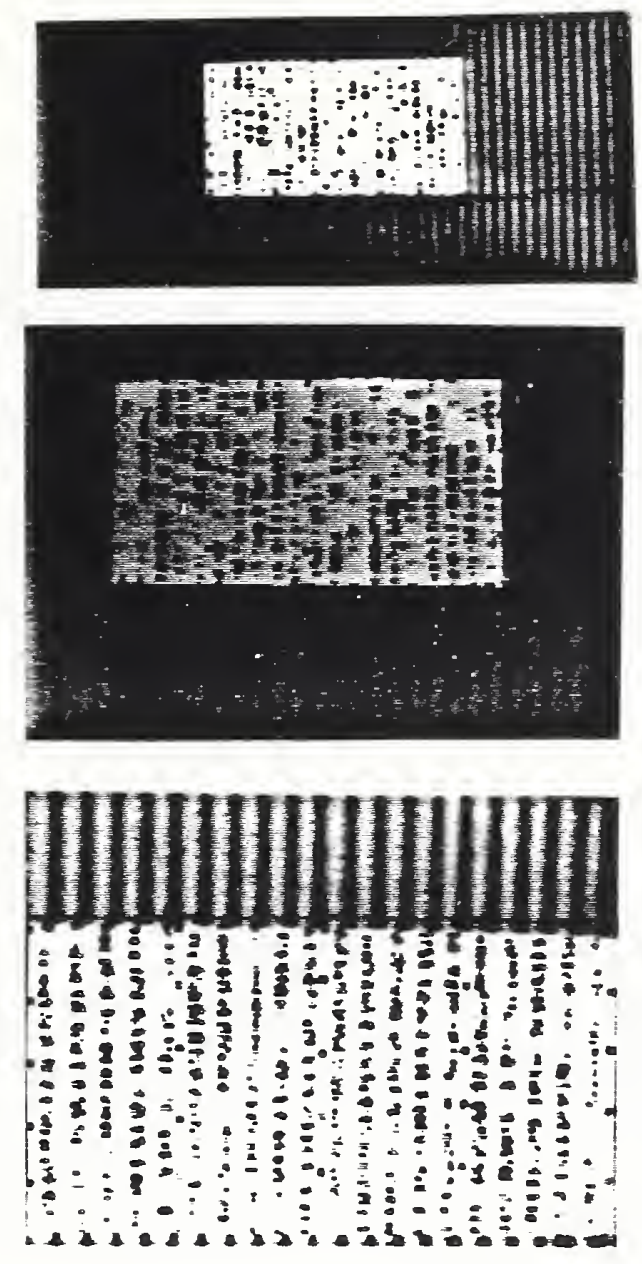

Fig. 11. Side of building from three different distances.

the database and the knowledge base so that maintenance decisions can be made on the basis of extent of degradation. By crossreferencing the degradation data with geographical and environmental data, it should be possible to qualitatively determine the effects of these factors on the degradation of various types of structures. The database should also contain an index of the images which have been stored so that the user of the system can recall images showing the degradation history of a structure.

The expert system could also benefit from the data provided by the image processing system. As the degradation is monitored over time, the success of various maintenance strategies can be evaluated and the knowledge base updated to reflect the new knowledge. The ability of the automated maintenance system to evaluate material performance, for example, may assist in the selection of materials for new structures. The stored images could also be accessed by the expert system for demonstrating various degradation modes and for training new personnel. 



\section{SUMMARY}

The application of computer image processing to the exterior condition assessment of metal buildings and roofing systems has been discussed. A summary of computer image processing, including discussions of hardware and software, has been provided as background information for maintenance personnel. The special concerns in applying computer image processing to condition assessment have been addressed and the ability of computer image processing to successfully quantify the degradation of coated surfaces and roofs has been demonstrated. Lastly, the potential of an integrated system combining image processing with database management and expert systems to automate a maintenance management program was discussed.

As with any new endeavor, initially a large amount of resources will need to be allocated to set up an image processing system for exterior condition assessment. Since there are a large number of image processing systems (hardware and software) on the market, however, it should be possible to initiate the program fairly quickly. Once standard procedures are developed the condition assessment process should become straightforward.

\section{ACKNOWLEDGEMENTS}

This investigation was conducted under the Tri-services Building Materials Investigational Program and was jointly sponsored by the Headquarters, US Army Corps of Engineers; US Navy, Naval Facilities Engineering Command, and US Air Force, Air Force Engineering and Services Center. The authors also acknowledge the diligent efforts of their colleagues, Mr. Edward Embree and Mr. Mike Hocker, for obtaining and processing the images used in this paper. 

(1) Mcknight, M.E., Mathey, R.G., and Drisko, R.W., "Preliminary Recommendations for Maintenance of Factory Coated Metal Siding and Roofing," NBSIR 85-3193, National Bureau of Standards, June 1985.

(2) Schowengerdt, R.A., "Techniques for Image Processing and Classification in Remote Sensing," Academic Press, Inc., New York (1983).

(3) Bentz, D.P., and Martin, J.W., "Using the Computer to Analyze Coating Defects," Journal of Protective Coatings and Linings $4(5): 38$ (1987).

(4) Federation of Societies for Coatings Technology, "Pictorial Standards for Coatings Defects", Federation of Societies for Coatings Technology, 1315 walnut street, suite 832, Philadelphia, PA (1979).

(5) SSPC-Vis 2-68T, "Standard Method of Evaluating Degree of Rusting on Painted steel surfaces," steel structures Painting Council, 4400 Fifth Av., Pittsburgh, PA (1970). 

BATCH IMAGE PROCESSING- Image processing involving the execution of a series of commands to access, preprocess, enhance, and classify and image.

BINARY IMAGE - A high-contrast image in which each pixel is assigned one of two values (e.g. 0-black and 255-white).

DIFFERENTIATION - An image processing algorithm in which each pixel is assigned the absolute value of the maximum difference between the original greylevel values of that pixel and each of its neighbors.

EXPERT SYSTEM - An interactive computerized system that uses KNOWLEDGE and INFERENCE procedures to solve specialized problems that require the knowledge of an expert.

FILTERING - An image processing neighborhood operation in which the output value for each pixel depends on the greylevel values of a neighborhood of surrounding pixels and a discrete weighting function (the filter). Examples include low and high pass filters.

FRAME BUFFER - The memory allocated for the storage of the greylevel values of all the pixels in a digitized image.

GREYLEVEL HISTOGRAM - A histogram of the number of pixels in an area of interest assigned to each of the available greylevel values. Peaks in such a histogram often correspond to the greylevel values occupied by defects of interest.

GREYLEVEL RESOLUTION - The number of different greylevel values an image processing system is capable of producing. Typical values are $8,16,64$, and 256 .

IMAGE CLASSIFICATION - The analysis of an image to obtain the desired final result such as the number, size, and type of defects.

IMAGE ENHANCEMENT - The modification of an image to produce a resultant image in which features of interest are easily detectable.

INFERENCE - The process of matching or linking knowledge (facts or data) to rules to form conclusions specific to the problem. 

INTERACTIVE IMAGE PROCESSING - Image processing in which an operator subjectively performs sequential operations to access, preprocess, enhance, and classify an image.

KNOWLEDGE BASE - Facts and rules contained in an expert system specific to the problem domain. This information serves as the basis for decision making.

LOOKUP TABLE - An input/output system where the output value(s) are dependent on the input entry (or entries). IRS tax tables are an example of a lookup table (LUT) where the output (the tax you owe) is dependent on the inputs (your income and number of dependents).

NEIGHBORHOOD OPERATIONS (LOCal operations) - Image processing algorithms in which the output value of each pixel is a function of the original greylevel values of that pixel and those pixels in its neighborhood. Filtering is an example of a neighborhood operation.

PIXEL - A pixel is an individual display unit. In image digitalization, each pixel is assigned a greylevel value (e.g. 0-255) based on the intensity of the incoming signal.

POINT OPERATIONS (Pixel operations) - Image processing algorithms in which the output greylevel value for each pixel is a function only of that pixel's original greylevel value. An example of a point operation is thresholding.

PREPROCESSING - The execution of image processing program, such as time averaging and background subtraction, in advance of another program which will perform most of the programming.

SPATIAL RESOLUTION - The ability of a digitized image to separate two close objects in an image; that is, it is a measure of the image processing system's ability to define the details of an image.

THRESHOLDING - An image processing point operation in which each pixel is assigned one output value $(e . g .0)$ if its original greylevel value is below a specified threshold value and a second value (e.g. 255) if its original output value is above this threshold. The result is a BINARY IMAGE.

VOLATILE DISPLAY (Refresh display) - An output display in which the image is continuously updated such as a TV or CRT screen. 

APPENDIX B - IMAGE PROCESSING BIBLIOGRAPHY

Bolc, L.: Kulpa, Z., "Digital Image Processing systems," Springer-Verlag, New York (1981).

Castleman, K. R., "Digital Image Processing," Prentice-Hall, Inc., Englewood Cliffs, NJ (1979).

Chang, N., "Image Analysis and Image Database Management," UMI Research Press, Ann Arbor, MI (1981).

Duff, M.J.B.; Levaldi, S., "Languages and Architectures for Image Processing," Academic Press, Inc., New York (1981).

Ekstrom, M. P. [ed.], "Digital Image Processing Techniques," Academic Press, Inc., New York (1984).

Gonzalez, R. and Wintz, P., "Digital Image Processing," AddisonWesley Publishing Co., Inc., Reading Mass. (1977).

Green, W. B., "Digital Image Processing- A Systems Approach," Van Nostrand Reinhold Co., New York (1983).

Hord, R. M., "Digital Image Processing of Remotely Sensed Data," Academic Press, Inc., New York (1982).

Huang, T.S., "Advances in Computer Vision and Image Processing," Jai Press, Inc. (1986).

Offen, P. J., "VLSI Image Processing," McGraw-Hill Book Co., New York (1985).

Oosterlink, A.; Danielsson, P. [eds.], "Architecture and Algorithms for Digital Image Processing," Society for Photooptical Instrumentation Engineers, Bellingham, WA (1983).

Schowengerdt, R.A., "Techniques for Image Processing and classification in Remote Sensing," Academic Press, Inc., New York (1983).

Young, T.S.; Fu, K., "Handbook of Pattern Recognition and Image Processing," Academic Press, Inc., New York (1986). 



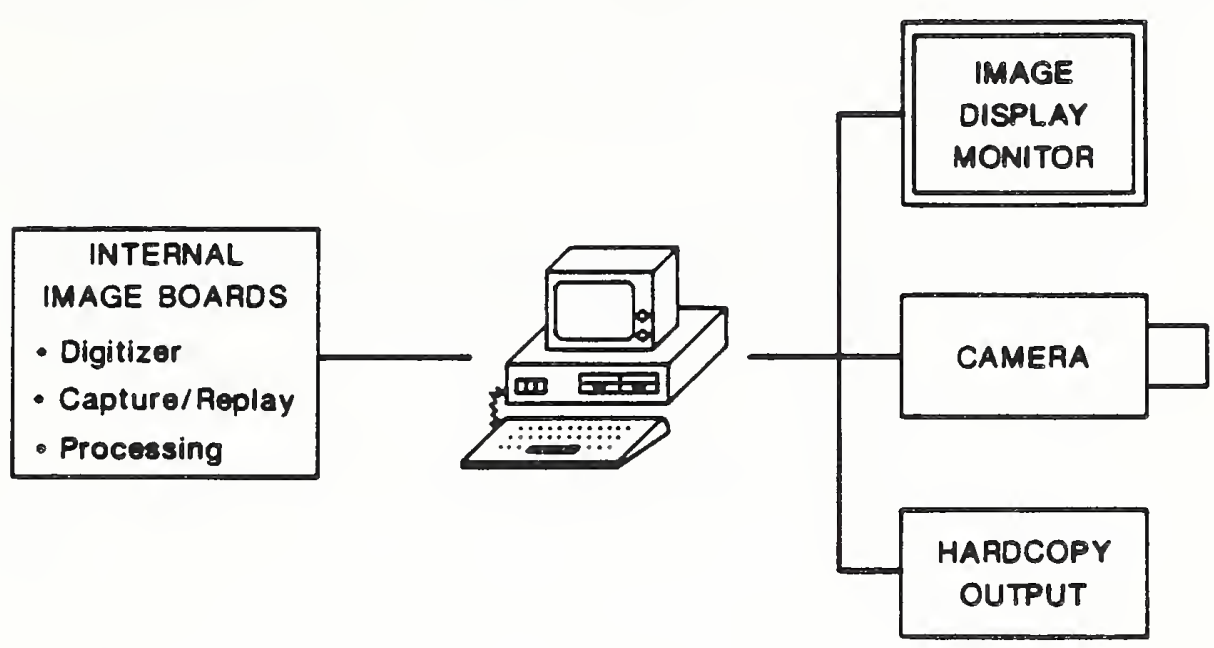

Fig. Cl. Sample PC-based computer image processing system.

MINICOMPUTER-BASED IMAGE PROCESSING SYSTEM

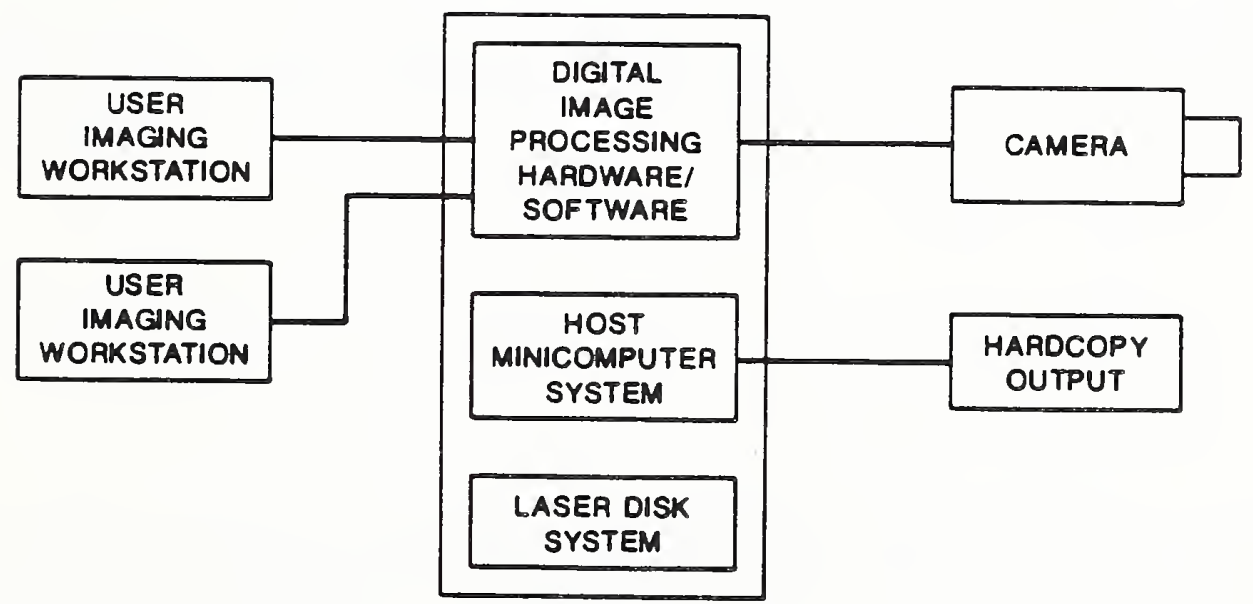

Fig. C2. Sample Minicomputer-based computer image processing system. 

BIBLIOGRAPHIC DATA

SHEET (See in struction S)

NBSIR 88-3719

4. TITLE AND SUBTITLE An Automated Maintenance Management Program Part I: Quantitative Assessment of the Exterior Condition of Metal Buildings and Roofing Systems Via Computer Image Processing

5. AUTHOR(S)

Jonathan W. Martin, Dale P. Bentz, Lawrence Kaetzel and Mary E. McKnight

6. PERFORMING ORGANIZATION (If joint or other than NBS, see instructions)

7. Coneracd Grant No.

\section{NATIONAL BUREAU OF STANDARDS \\ U.S. DEPARTMENT OF COMMERCE \\ GAITHERSBURG, MD 20899}

9. SPONSORING ORGANIZATION NAME AND COMPLETE ADDRESS (Street, City. State, ZIP)

Tri-Services Building Materials Investigational Program

Department of Defense

\section{SUPPLEMENTARY NOTES}

Document describes a computer program; SF-185, FIPS Software Summary, is attached.

11. ABSTRACT (A 200-word or less factual summary of most significant information. If document includes a significant bibliography or literature survey. mention it here)

Automation of a maintenance management program could result in considerable benefits in terms of time, money, and aesthetics to any facilities' maintenance program. An integrated system combining computerized condition assessment, database management, and expert systems could serve to automate the maintenance management process. One part of such a system, the use of computer image processing to quantitatively assess the exterior condition of buildings, is presented. Computer image processing hardware and software are reviewed and the special concerns present in applying image processing to condition assessment are addressed. Examples of the capability of image processing to quantify the degradation of coated surfaces and roofing systems are presented. Finally the integration of image processing into an overall automated maintenance management program is discussed.

12. KEY WORDS (Six to twelve entries; alphabetical order: copitalize only proper names; and seporate key words by semicolons) automated maintenance management program; computer image processing; condition assessment; database management; degradation; exterior envelope; sampling procedures

\section{AVAILABILITY}

Xnlimited

$\square$ For Official Distribution. Do Not Release to NTIS

$\square$ Order From Superintendent of Documents, U.S. Government Printing Office, Washington. D.C. 20402.

X Order From National Technical Information Service (NTIS), Springfield, VA. 22161
14. NO. OF

PRINTED PAGES 28

15. Price

$\$ 11.95$ 




MICANAM

P

3.94 
